\title{
IMPORTÂNCIA DAS TEORIAS AGRÁRIAS PARA A GEOGRAFIA RURAL
}

\author{
Msc. Flamarion Dutra Alves \\ Doutorado em Geografia da UNESP - Campus Rio Claro. \\ Núcleo de Estudos Agrários - NEA. Departamento de Geografia - UNESP \\ Av. 24-A, 1515. Bairro Bela Vista - CEP.13506-900, Rio Claro (SP), Brasil. \\ Tel.: (19) 3523-3707 - dutrasm@yahoo.com.br \\ Prof. Dr. Enéas Rente Ferreira \\ eneasrf@rc.unesp.br
}

\begin{abstract}
RESUMO
Este artigo abordará, pautado nos trabalhos clássicos de Kautsky, Lênin e Chayanov, os processos capitalistas na agricultura e suas dinâmicas na questão agrária. O objetivo é o de verificar o quadro atual do espaço agrário brasileiro, aprofundando discussão sobre a inserção do modo de produção capitalista no campo e a importância dessas teorias na geografia.
\end{abstract}

Palavras-Chave: Teorias Agrárias, Capitalismo, Agricultura, Geografia Rural, Metodologia.

\begin{abstract}
This paper will approach the capitalist processes in agriculture and its dynamic in the agrarian question under the optics of rural classics of Kautsky, Lenin and Chayanov, beyond verifying the current scene of Brazilian agrarian space, in order to deepen the quarrel on insertion in way of capitalist production in agrarian space and the importance of these theories in geography.

Key word: Agrarian Theories, Capitalism, Agriculture, Rural Geography, Methodology.

\section{RÉSUMÉ}

Cet article présentera les procès capitalistes dans l'agriculture et leur dynamiques à propos du sujet agraire sur l'optique des oeuvres classiques ruraux de Kautsky, Lênin et Chayanov, et puis il vérifiera le cadre actuel agraire brésilien, à fin d'approfondir la discussion sur l'insertion du mode de production capitaliste à la campagne et l'importance de ces théories à la géographie. Ainsi, la base de la discussion est centrée sur "La Question Agraire" (1899) de Karl Kautsky, "Le Development du Capitalisme dans la Russe" (1899) de Vladimir Ilich Lênin et l'oeuvre "L'Organisation de l'Unité Economique Campagnarde" (1925) de Alexander Chayanov, qui sont des réferences fundamentaux dans la thématique agraire.
\end{abstract}

Mots Clé: Théories Agraires, Capitalisme, Agriculture, Géographie Rural, Méthodologie.

\section{Introdução}

A leitura de obras de autores clássicos (Kautsky, Lênin e Chayanov, os dois primeiros publicados em 1899 e o último em 1925), dá-se com o objetivo de, a partir da discussão da questão agrária e do desenvolvimento do capitalismo no campo, verificar elementos pertinentes ao processo agrário contemporâneo e sua relevância no estudo geográfico.

A análise dessas obras e das teorias a respeito da influência do capitalismo no campo são bases para o entendimento do processo de modernização do campo, da concentração fundiária, da integração agricultura-indústria, exclusão do homem do campo no processo capitalista, êxodo rural, territorialização do capital no campo, ou seja, o maior entendimento sobre a questão agrária e a interface com a organização do espaço geográfico.

Em suma, se trata de reflexão acerca de teorias que dão suporte às metodologias na geografia rural, buscando colaborar tanto no aprofundamento dos debates metodológicos, como na compreensão da dinâmica das transformações no espaço. 


\section{Pressupostos teóricos dos clássicos rurais}

A definição das teorias agrárias de Kautsky, Lênin e Chayanov serão orientadas de forma sintética, buscando compreender a idéia central contida nas obras, para assim, realizar observações atinentes aos objetos de estudo da geografia rural.

Ao enfocar as questões contraditórias do capitalismo na construção do espaço agrário, o papel dessas obras nas concepções teóricas da geografia rural é reforçado nas pesquisas e estudos desenvolvidos na corrente crítica da geografia.

\section{Tese de Kautsky da superioridade da grande propriedade}

Em sua obra "A Questão Agrária”, publicada em 1899, Karl Kautsky descreve a influência do capitalismo sobre a agricultura e as transformações ocorridas no campo russo no final do século XIX. O autor faz prognósticos para o novo século que se aproximava, baseado nos resultados de suas investigações sobre o campesinato russo e a introdução do capitalismo nas atividades agrícolas.

Em linhas gerais, a idéia central de Kautsky (1972) é a de que a grande propriedade rural tem superioridade técnica em relação à pequena, sendo a que melhor se adapta à penetração do capitalismo no campo e, por conseguinte à inserção inevitável da "industrialização da agricultura". Nesse sentido, a pequena propriedade tenderia a diminuir ou desaparecer.

Kautsky (1972) descreve as conseqüências diretas dos desequilíbrios da produção capitalista no campo, notadamente as oscilações e inseguranças enfrentadas pelos camponeses ao se inserirem nos moldes do sistema capitalista e as dificuldades em competir com o grande proprietário.

Como conseqüências do capitalismo no campo ou sinais de sua evolução, pode-se citar: os processos de integração agricultura-indústria, a dependência intersetorial, extermínio ou diminuição da pequena produção camponesa, surgimento de manufaturas e objetos industrializados para a produção agrícola, aumento do êxodo rural e o aumento de empregos nos centros urbanos a oferecerem melhores remunerações e condições de vida.

Esse processo determinou um novo ritmo na vida do camponês e Kautsky (1972, p.26) afirma que "quanto mais esse processo avança, mais se dissolve a indústria doméstica (...) e mais aumenta a necessidade de dinheiro para o camponês", ou seja, a obrigatoriedade crescente do camponês obter capital para realizar suas atividades agrícolas.

Kautsky (1972) se mostra consciente do fato de que no campo as formas de produção capitalista avançam inexoravelmente, e tem claro o problema da concorrência dos Estados Unidos com os mercados agrícolas europeus. A territorialização dos produtos e serviços estadunidenses no espaço agrário europeu aumentaria a disputa entre os produtores rurais europeus, e com isso o grande proprietário colocar-se-ia em vantagem em relação ao camponês.

Já prevendo a inserção do capitalismo na agricultura, com produção regida pela dinâmica industrial, Kautsky afirma que: "a grande exploração agrícola é a que melhor satisfaz as necessidades da grande indústria agrícola. Essa, muitas vezes, quando não tem uma grande exploração deste gênero à sua disposição, a cria" (KAUTSKY, 1972, p.124). Desse modo, tem-se uma integração agricultura-indústria, implicando em envolvimento do camponês pelo sistema capitalista, deixando de ser camponês de subsistência e se transformando em trabalhador assalariado na cidade ou agricultor voltado à produção do mercado. Dependente de atributos que não dispunha, deixa de ser ator principal da produção, sendo suprimido, em grande parte, pela tecnificação. Após essas mudanças, o camponês para Kautsky:

[...] deixa portanto de ser o senhor da sua exploração agrícola: esta torna-se um anexo da exploração industrial pelas necessidades da qual se deve regular. O camponês torna-se um operário parcial da fábrica [...] ele cai ainda sob a dependência técnica da exploração industrial [...] lhe fornece forragens e adubos. Paralelamente a esta dependência técnica produz-se ainda uma dependência puramente econômica do camponês em relação à cooperativa (KAUTSKY, 1972, p.128-129). 
Kautsky (1972) ao se questionar sobre a função destes atores no interior da sociedade capitalista, não esqueceu as formas pré-capitalistas e não-capitalistas da agricultura. O que fazer com esses camponeses, não integrados totalmente no sistema? Qual sua função no sistema?

Nesse sentido, estabelece contraponto entre a pequena e a grande exploração e afirma que "quanto mais o capitalismo se desenvolve na agricultura, mais aumenta a diferença qualitativa entre a técnica da grande e da pequena exploração" (KAUTSKY, 1972, p.129). Chega a realizar previsões sobre a pequena propriedade, apresentando-a como condenada ao desaparecimento face à superioridade da grande fazenda capitalista.

As transformações que ocorrem na agricultura com a integração industrial tornam o agricultor mais vulnerável e dependente do capital, dessa forma, ao mencionar a transformação na agricultura ressalta que:

qualquer progresso nesse sentido terá necessariamente como resultado o agravamento do estado de crise em que se encontram os agricultores, o aumento da sua dependência em relação à indústria, a diminuição da segurança da sua existência (KAUTSKY, 1972, p.160).

Kautsky ao sinalizar para a evolução do modo capitalista na agricultura, não prega o o fim da pequena propriedade, ao contrário, a grande exploração necessita de pequenas propriedades para a exploração industrial, as quais fornecem tanto matéria prima à indústria como mão-de-obra nos períodos em que a grande exploração necessita de assalariados (KAUTSKY, 1972).

O autor também enfoca o processo de diferenciação social, e, apesar de admitir a superioridade da grande empresa, deixa clara a possibilidade de sobrevivência da pequena empresa familiar, sobretudo se esta for capaz de se associar e cooperar (Figura 1).

Figura 1 - Organograma: Principais idéias na teoria agrária de Kautsky (1899)

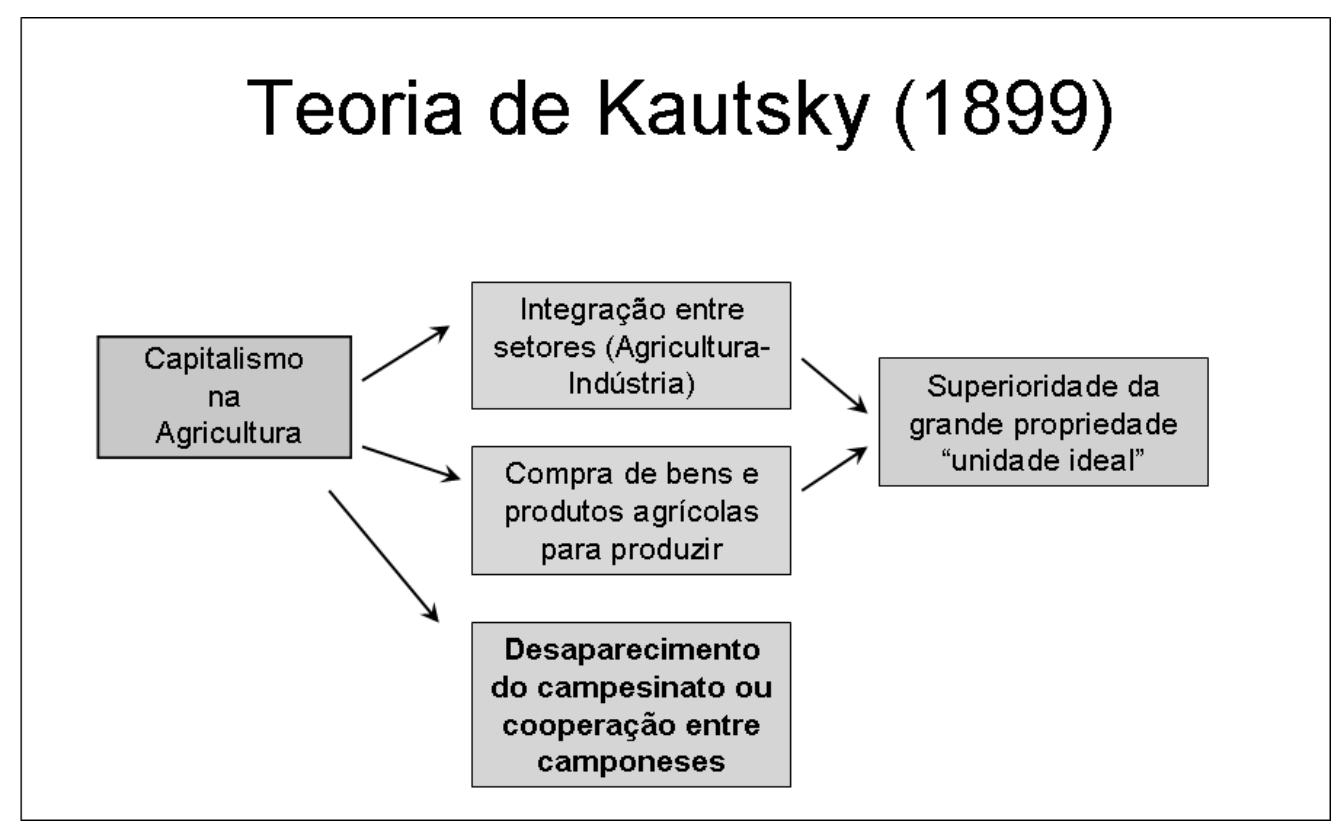

Fonte: Kautsky (1972) Organização: Flamarion Dutra Alves

Para isso, Kautsky (1972) sugere a organização dos camponeses em ligas e no sentido de superarem as dificuldades da industrialização na agricultura, ou seja, uma organização coletiva do campo ou organização 
socialista da produção com vistas ao enfrentamento do capitalismo agrário.

\section{Tese leninista da desintegração do campesinato}

Outra teoria agrária, considerada como um dos clássicos rurais é a obra de Vladimir Ilich Lênin, " $O$ Desenvolvimento do Capitalismo na Rússia”, publicada em 1899. Nela é analisada a formação do mercado para o capitalismo, demonstrando ser a desintegração do campesinato um processo determinado pelas relações de produção em direção ao capitalismo. Ainda nessa obra, o autor analisa as conseqüências mais importantes da inserção desse processo na agricultura.

Lênin realizou seu estudo considerando as propriedades rurais da Rússia e indicou que o processo capitalista provocava uma "decadência do estabelecimento, a ruína do camponês e sua transformação em operário, além da ampliação da unidade agrícola e a transformação do camponês em empresário rural" (LÊNIN, 1985, p.83), ou seja, a modificação do padrão de produção das propriedades e da necessidade de capital para a sobrevivência do homem no campo.

No capítulo II de sua obra, intitulado “A Desintegração do Campesinato” Lênin aborda a situação do camponês frente ao processo capitalista, indicando um camponês inteiramente subordinado ao mercado, à economia mercantil: tanto para consumo de produtos necessários a ele como à atividade agrícola. Essa transformação, desintegração do campesinato, gera um mercado interno para o capitalismo.

O processo de desintegração do campesinato foi conseqüência de diversos fatores, indicados em conjunto de dados sobre "arrendamento, compra de terras, implementos agrícolas aperfeiçoados, atividades temporais, o progresso da agricultura mercantil, o trabalho assalariado" (LÊNIN, 1985, p.94). Pautado nessas informações Lênin formula a tese da desintegração do campesinato na Rússia associada ao empobrecimento do camponês, representado processo que para ele:

não era antagônico ao capitalismo, mas, ao contrário, é a sua base mais profunda e sólida. A mais profunda porque é no seu interior mesmo, [...] que constatamos a formação constante de elementos capitalistas. A mais sólida porque é sobre a agricultura em geral e o campesinato em particular que pesam mais intensamente as tradições da Antiguidade, [...] é aí que a ação transformadora do capitalismo se manifesta mais lenta e mais gradualmente (LÊNIN, 1985, p.113).

Essas transformações decorrentes do processo capitalista no campo fazem com que ocorram mudanças nas classes sociais rurais. Nesse sentido afirma que:

o campesinato antigo não se "diferencia” apenas: ele deixa de existir, se destrói, é inteiramente substituído por novos tipos de população rural, que contribuem à base de uma sociedade dominada pela economia mercantil e pela produção capitalista (LÊNIN, 1985, p.114).

Para o autor, com o avanço do capitalismo, a forma tradicional e típica do campesinato russo deixou de existir. Anecessidade da aquisição de capital pelos camponeses alterou a rotina de trabalho, os processos, objetivos e destinos da produção agrícola, conseqüentemente, os grandes proprietários têm as melhores condições para enfrentar o sistema capitalista na agricultura (Figura 2).

O estudo de Lênin mostra que o desenvolvimento do capitalismo na agricultura suscitou um antagonismo nas classes sociais rurais. Havendo uma oposição de classes, de um lado, a burguesia rural e, de outro, os operários agrícolas. Conforme Lênin "os agricultores se metamorfoseiam cada vez mais depressa em produtores submetidos às leis gerais da produção mercantil” (1985, p. 202).

Assim, a tese leninista se baseia na desintegração do campesinato, fruto da criação de um mercado interno para o capitalismo e ocasionando a diferenciação social no campo e o crescimento das grandes propriedades, na medida em que se desintegram os camponeses. Para Lênin, com o avanço do modo de produção capitalista, o desaparecimento do campesinato é inevitável, abandonando os camponeses suas propriedades rurais para trabalhar na grande propriedade ou nas fábricas dos centros urbanos. 
Figura 2 - Organograma: Principais idéias na teoria agrária de Lênin (1899).

\section{Teoria de Lênin (1899)}

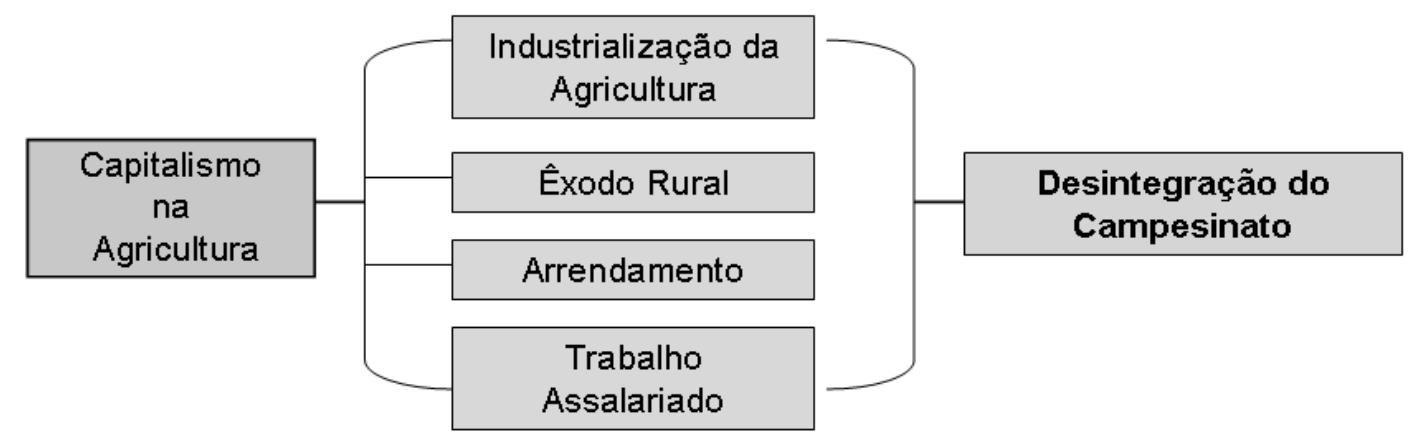

Fonte: Lênin (1985)

Organização: Flamarion Dutra Alves

\section{Reprodução do campesinato em Chayanov}

No contexto de reprodução e resistência camponesa, destaca-se o estudo de Alexander Chayanov "A Organização da Unidade Econômica Camponesa", publicada em 1925. Constitui importante referencial teórico sobre a questão camponesa e coloca como elemento fundamental, a caracterização do campesinato a partir do núcleo familiar e do balanço trabalho-consumo existente na unidade doméstica.

Chayanov (1974), não parte do princípio da subordinação dos camponeses pela renda da terra e de sua inserção na dinâmica capitalista. A circulação da produção camponesa, onde reside sua subordinação ao capital e a conseqüente expropriação do camponês, é considerada "marginal" na sua compreensão. O autor parte da necessidade do consumo, a subsistência da família para entender o trabalho camponês e a conseqüente reprodução familiar.

A teoria da organização da unidade econômica camponesa de Chayanov se baseia nos estudos desenvolvidos sobre as economias de produção familiares russas, no início do século XX. Essa teoria, fundamenta-se no entendimento de que a família trabalha para preencher as necessidades fundamentais dos seus membros e em um segundo plano, para acumular capital. Considerando a ausência do trabalho assalariado e a não acumulação de capital, Chayanov classifica a unidade econômica camponesa como não-capitalista.

A dinâmica da relação consumo-produção em uma unidade familiar explica seu incremento na consideração do número de trabalhadores da família, números de consumidores e da necessidade de consumo, que justificariam a expansão dos cultivos.

Dessa forma, a renda baseada no lucro médio poderia ser renunciada pelos camponeses, que sobreviveriam para atender suas necessidades básicas de consumo e não para garantir renda compatível com a taxa de lucro médio (CHAYANOV, 1974). 
A explicação da racionalidade camponesa para Chayanov é referente a uma diferenciação demográfica, ou seja, o número de trabalhadores e consumidores da família camponesa é a explicação da sua existência: um trabalho que serve às demandas necessárias à manutenção da família e não a produção de valor e acumulação de capital.

A força de trabalho da família é o elemento mais importante no reconhecimento da unidade camponesa. A família define o máximo e o mínimo da atividade econômica da unidade, o tamanho da família (número de consumidores) tem relação direta com a atividade econômica da unidade de produção. Portanto, a produção camponesa possui uma dinâmica diferenciada e particular, e reconhecida pela diferenciação demográfica no balanço trabalho-consumo (equação braços e bocas).

Chayanov reconhece encontra-se o campesinato fora do modo de produção capitalista. Afirma que o campesinato é um modo de produção, cujas características são: a força do trabalho familiar - unidade econômica camponesa -, pequena propriedade como local das atividades, a própria família produz seu meio de produção, às vezes, devido a diversos fatores, membros da família se vêem obrigados a empregarem sua força de trabalho em atividades rurais não-agrícolas.

Portanto, a atividade econômica camponesa não se assemelha a de um empresário rural, à busca de geração de lucro ao investir seu capital recebendo uma diferença entre a entrada bruta e os gastos gerais de produção. Trata-se de uma simples remuneração que permite ao mesmo determinar o tempo e a intensidade do trabalho, ou seja, a lógica camponesa não é de acumulação de capital, mas reprodução de seu modo de vida e independente das relações capitalistas.

O aumento da produtividade do trabalho camponês se deve à pressão exercida pelas necessidades do consumo familiar. Nesse sentido, a lógica da organização da unidade econômica camponesa se baseia na racionalização entre os aspectos quantidade e qualidade de terra, força de trabalho e capital. Qualquer distorção nesta relação é compensada seja com ocupação da força de trabalho em atividades não-agrícolas complementares, seja pela intensificação do trabalho. (Figura 3).

Figura 3 - Organograma: Principais idéias na teoria agrária de Chayanov (1925).

\section{Teoria de Chayanov (1925)}

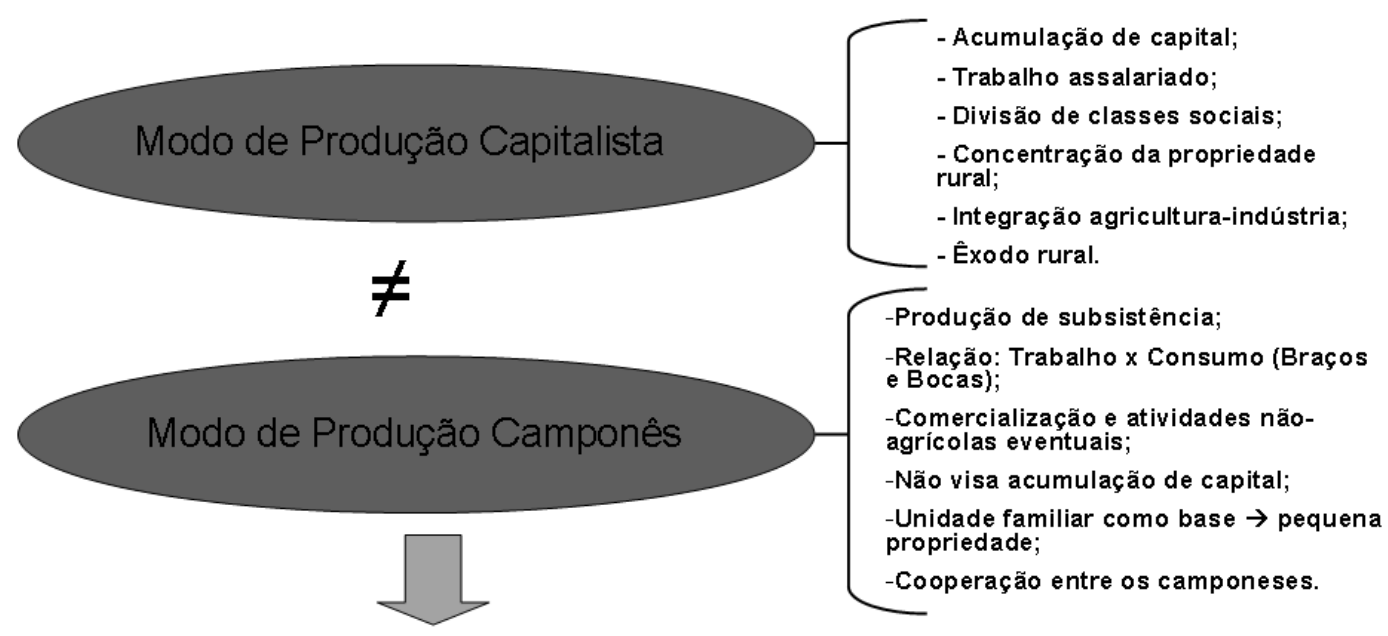

Unidade Econômica Camponesa $\rightarrow$ Não Capitalista

Fonte: Chayanov (1974)

Organização: Flamarion Dutra Alves 
Para concluir, Chayanov vê nas cooperativas coletivas as únicas alternativas para introduzir a exploração camponesa no ambiente da industrialização agrícola em grande escala. Assim, para permanecer no modo de produção camponesa o caminho è a unidade econômica camponesa familiar e em caso de ingresso no modo de produção capitalista, os camponeses devem se aliar e unir em cooperativas.

\section{Processo capitalista na agricultura e a leitura dos clássicos rurais}

Após as leituras das obras clássicas de Kautsky (1972), Lênin (1985), Chayanov (1974) faz-se uma breve consideração sobre a inserção do capitalismo na agricultura (Quadro 1).

Quadro 1- Comparação das obras de Kautsky, Lênin e Chayanov sobre a questão agrária

\begin{tabular}{|c|c|c|c|}
\hline & KAUTSKY & LÊNIN & CHAYANOV \\
\hline Obra & A ques tão agrária & $\begin{array}{l}\text { O desenvolvimento do } \\
\text { capitalismo na Rússia }\end{array}$ & $\begin{array}{l}\text { A organização da unidade econômica } \\
\text { camponesa }\end{array}$ \\
\hline Lançamento & 1899 & 1899 & 1925 \\
\hline Idéia central da obra & $\begin{array}{l}\text { Superioridade técnica da } \\
\text { grande propriedade. }\end{array}$ & $\begin{array}{l}\text { Desintegração do } \\
\text { campesinato. }\end{array}$ & $\begin{array}{l}\text { Teoria da unidade econômica } \\
\text { camponesa. }\end{array}$ \\
\hline $\begin{array}{l}\text { Cons eqüências para os } \\
\text { camponeses com o ava nço } \\
\text { capi talista }\end{array}$ & $\begin{array}{l}\text { Expansão das grandes } \\
\text { fazendas capital istas, mas } \\
\text { não o desaparecimento } \\
\text { total da pequena } \\
\text { propriedade. }\end{array}$ & $\begin{array}{l}\text { Desintegração total do } \\
\text { campesinato em cons eqüência } \\
\text { da grande exploração } \\
\text { capitalista. }\end{array}$ & $\begin{array}{l}\text { Aumento de unidades econômicas } \\
\text { familiares. }\end{array}$ \\
\hline $\begin{array}{l}\text { Des tino ou saída para os } \\
\text { camponeses } \\
\text { capi talismo }\end{array}$ & $\begin{array}{l}\text { Formação } \\
\text { cooperativas. }\end{array}$ & $\begin{array}{lr}\text { Desintegração dos } \\
\text { camponeses pobres em favor } \\
\text { da burguesia rural, } \\
\text { assalariamento. }\end{array}$ & $\begin{array}{l}\text { Manutenção da unidade econômica } \\
\text { camponesa ou a formação de } \\
\text { cooperativas coletivas. }\end{array}$ \\
\hline
\end{tabular}

Fonte: Alves (2006, p.63)

As teorias de Kautsky e Lênin apontam para o avanço das relações capitalistas no campo, com implementação de lógica da superioridade das grandes propriedades e indicação de tendência de diminuição ou desaparecimento dos camponeses e pequenos proprietários rurais. Já Chayanov, ao estudar a unidade econômica camponesa familiar, afirma o contrário, acreditando que o camponês continuará a existir e com a associação e cooperação entre os mesmos há tendência de fortalecimento, formando um modo de produção independente do capitalista.

Chayanov (1974) defende a tese da produção camponesa em sua base, já os estudos marxistas (Kautsky e Lênin) apontam para a compreensão do campesinato no interior das relações capitalistas no campo e não como um modo de produção.

Lênin e Kautsky defendem que os pequenos proprietários familiares são conduzidos ao empobrecimento e assalariamento com o desenvolvimento do capitalismo no campo, conseqüência da falência da pequena exploração em benefício da grande exploração agrícola capitalista, posto se ajustar melhor, devido ao tamanho da propriedade e a produção em escala, ao modo de produção capitalista.

Chayanov diferencia-se de Lênin com relação à base demográfica do rural. O primeiro não via o desaparecimento dos camponeses, com a inserção ou penetração do capitalismo no campo, vislumbrava o aumento dos estabelecimentos de economia familiar, posto a produção camponesa depender do trabalho familiar para sua subsistência. O segundo baseava-se na desintegração do campesinato com o desenvolvimento do capitalismo, ou seja, seu desaparecimento no decorrer do processo capitalista e em 
função da expansão das atividades mecânicas e industriais na agricultura.

\section{Geografia rural: teorias agrárias e metodologia}

O referencial teórico utilizado na geografia rural brasileira se destaca pela heterogeneidade das áreas do conhecimento. A fundamentação baseada em autores e teorias da sociologia rural, economia rural, agronomia, antropologia rural entre outras são constantemente consultadas pelos geógrafos que trabalham com a temática agrária ${ }^{1}$.

Considerando que a escolha do método em uma pesquisa está intrinsecamente ligado ao referencial teórico, faremos algumas ponderações a respeitos das teorias agrárias de Kautsky, Lênin e Chayanov com a metodologia na geografia rural.

Embora concorde-se com Andrade (1995, p.11), de que "não é fácil elaborar um esquema de teorização e de metodologia único para a Geografia Rural ou para qualquer outro tema, sobretudo no momento de grandes transformações em que se vive", nos serviremos deste procedimento para elucidar algumas questões teórico-metodológicas.

Devido as diferentes opiniões e visões acerca da produção do espaço agrário, as teorias agrárias de Kautsky (1899), Lênin (1899) e Chayanov (1925) são importantes no debate agrário brasileiro atual. O referencial teórico das pesquisas a se utilizar desses clássicos rurais, deve levar em consideração um método que se preocupe com as relações socioeconômicas e a construção do espaço geográfico, ou seja, uma abordagem na qual a sociedade esteja no centro das questões (Figura 4).

Figura 4 - Organograma: Relação entre metodologia e objeto de estudo da geografia.

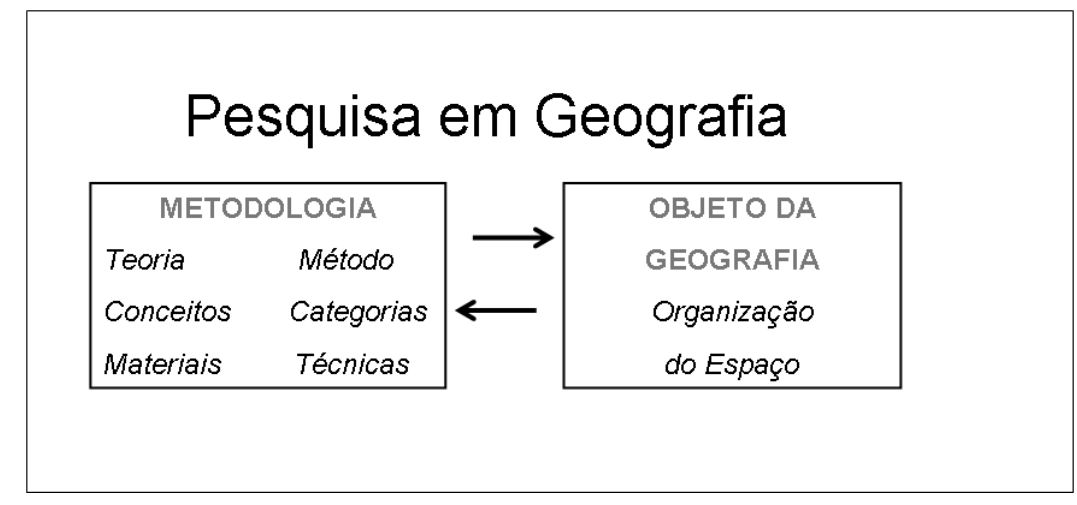

Organização: Flamarion Dutra Alves

Seguindo a lógica de Kautsky e Lênin, o agronegócio e a expansão das atividades agrícolas de exportação são os melhores exemplos da teoria propostas por eles. Amecanização e a grande propriedade frente aos mercados internacionais são os modelos de desenvolvimento da reprodução capitalista no campo.

Na geografia rural existem correntes que defendem a ocupação do espaço agrário pela agricultura moderna e "eficaz", capaz de industrializar e modernizar o campo através das inovações biotecnológicas e do agronegócio. Nessa concepção, a população rural trabalha para o empresário rural nas lavouras modernas ou migra para os centros urbanos. Aqui podemos citar as reflexões de Elias (2006) sobre esse processo no espaço agrário.

No início de um novo milênio, vive-se uma quebra dos principais paradigmas da relação homem-natureza e reforçam-se os questionamentos sobre a viabilidade do modelo de agricultura adotado no Brasil com o advento da globalização. Nenhum outro modelo promoveu tanta pobreza, desigualdades e degradação ambiental em tão pouco tempo; nenhum provocou uma crise de tantas magnitudes, no campo e nas 
cidades, a evidenciar a associação entre crescimento econômico e deterioração da situação social e ambiental, com o agravamento das contradições. (ELIAS, 2006).

Desde o início da década de 1960, essa agricultura científica e globalizada é resultado de diversos esforços para modernizar o campo: tanto com a Revolução Verde, como com os governos militares brasileiros beneficiando os grandes proprietários rurais com crédito abundante e financiamentos bancários.

Contrariando as teorias marxistas, Chayanov ressalta a importância da agricultura camponesa ou de cunho familiar. Sobre essa temática, a geografia rural tem um vasto material bibliográfico que defende a agricultura de subsistência, principalmente os geógrafos envolvidos com movimentos sociais no campo e pequenos proprietários rurais.

Além da subsistência destacada pela teoria de Chayanov, o autor lembra das atividades não-agrícolas, pluriatividade, como complemento na unidade econômica camponesa. A respeito dessas atividades há os trabalhos na geografia rural de Marafon $(2006,2007)$, salientando a importância da economia familiar dos agricultores, além da preservação do espaço agrário.

Todavia, deve-se ficar bem claro, que a teoria de Chayanov expressa um momento dos camponeses na Rússia no início do século XX e que a adoção de um modelo semelhante aos dessa teoria devem ser revisitados.

\section{Considerações Finais}

No contexto capitalista da agricultura se observa uma dualidade, resultante da desigualdade fundiária e financeira que o processo capitalista impôs no espaço agrário, entre camponeses e proprietários empresariais.

Através da leitura dos clássicos rurais sobre a inserção do capitalismo na agricultura se pôde vislumbrar alguns cenários para a atual conjuntura agrária. Diferentemente do que afirmaram Kautsky e Lênin o camponês não se extinguiu, pelo contrário, ampliaram-se as atividades familiares, reforçando, nos termos apresentados por Chayanov e Kautsky, a cooperação e associação entre os camponeses como saída para enfrentamento do avanço do capitalismo no campo.

As pesquisas em geografia rural podem auxiliar na caracterização e explicação do espaço agrário brasileiro e o uso dessas teorias são ferramentas importantes no esquema metodológico das investigações. O uso de diferentes métodos na geografia rural é conseqüência da pluralidade teórico-metodológica. Nesse artigo, destacamos as teorias agrárias marxista de Kautsky e Lênin, além da teoria da reprodução camponesa de Chayanov.

A evidência empírica dessas teorias são encontradas na produção científica da geografia rural, principalmente nas pesquisas que trabalham com o método dialético, no contexto da geografia crítica.

\section{Notas}

\footnotetext{
${ }^{1}$ Em um estudo realizado acerca da produção bibliográfica na geografia agrária, Ferreira (2001, p.42) debate a influência das outras ciências na base teórica das pesquisas em geografia agrária.
}

\section{Referência Bibliográfica}

ALVES, Flamarion D. Os impactos da territorialização dos assentamentos rurais em Candiota - RS. Dissertação (Mestrado em Extensão Rural). Santa Maria: Universidade Federal de Santa Maria, 2006.

ANDRADE, Manuel C. de. Geografia Rural; questões teórico-metodológicas e técnicas. p.3-14. In: Boletim de Geografia Teorética. v.25, n.49-50, 1995.

CHAYANOV, Alexander. La organización de la unidad económica campesina. Buenos Aires: Nueva Visión, 1974 (1925). 
ELIAS, Denise de S. Globalização e fragmentação do espaço agrícola no Brasil. Scripta Nova. Revista eletrônica de geografia y ciencias sociales. Barcelona. v.X, n.218(03), 2006.

FERREIRA, Darlene A. O. Geografia Agrária no Brasil: conceituação e periodização. p.39-70. Terra Livre. São Paulo. n. 16, $1^{\circ}$ semestre, 2001.

KAUTSKY, Karl. A Questão Agrária. Porto: Portucalense, 1972 (1899).

LÊNIN, Vladimir I. O desenvolvimento do capitalismo na Rússia: o processo de formação do mercado interno para a grande indústria. 2.ed. São Paulo: Nova Cultural, 1985 (1899).

MARAFON, Gláucio J. Agricultura familiar, pluriatividade e turismo rural: reflexões a partir do território fluminense. p.17-60. In: Campo-Território: Revista de Geografia Agrária. Uberlândia, v.1, n.1, 2006. v.IV, n.2, 2007.

Turismo em áreas rurais no estado do Rio de Janeiro. p.85-102. In: Ciencias Sociales Online.

Trabalho enviado em janeiro de 2009

Trabalho aceito em agosto de 2009 